\title{
Acanthomatous ameloblastoma - A case report
}

\author{
Rahul Tiwari ${ }^{1, *}$, Raja Satish Prathiguduppu ${ }^{2}$, Kiruba Shankar K ${ }^{3}$, Kritika Sehrawat ${ }^{4}$, Salud Sadique ${ }^{5}$ \\ ${ }^{\mathbf{1}}$ Fellow, ${ }^{2}$ Senior Registrar ${ }^{3,4} \mathrm{PG}$ Student, ${ }^{\mathbf{5}} \mathrm{Clinical}$ Observer, ${ }^{\mathbf{1 , 3 - 5}} \mathrm{Dept}$. of Oral and Maxillofacial Surgery, ${ }^{\mathbf{1 , 5}}$ Jubilee Mission \\ Medical College \& Research Centre, Thrissur, Kerala, ${ }^{2}$ Ministry of Health, Amiri Dental Casuality, Kuwait, ${ }^{3}$ KVG Dental \\ College and Hospital, Sullia, D.K, Karnataka, ${ }^{4}$ Sudha Rustagi Dental College and Research Centre, Faridabad, Haryana, India
}

*Corresponding Author:

Email: drrahulvctiwari@gmail.com

\begin{abstract}
Ameloblastoma is a common pathological disease of maxillofacial region. It is frequently seen in Asian continents, but huge variants are seen in African countries. Hereby we are presenting a case report of acanthomatous ameloblastoma operated for excision, curettage and chemical cauterization under general anesthesia.
\end{abstract}

Keywords: Ameloblastoma, Oral Pathology.

\section{Introduction}

Ameloblastoma is a true epithelial odontogenic tumor usually unicentric, nonfunctional, intermittent in growth, anatomically benign and clinically persistent. ${ }^{1}$ It usually consists of proliferating odontogenic epithelium usually with a follicular or plexiform pattern lying in a fibrous stroma. ${ }^{2}$ Cussack in 1827 was the first to recognize lesion of odontogenic origin. ${ }^{3}$ Malassez in 1855 first defined as adamantinoma. ${ }^{4}$ Ameloblastoma has predominancy to affect young people. ${ }^{5}$ Clinical presentation and characteristics regarding size, age, and sex distributions differs in the published literature..$^{6-8}$ Sex predilection also differs as some author suggests it is higher in men and some suggest both these sexes are equally affected. ${ }^{9-11}$ There are different radiologic and histologic patterns of ameloblastoma. Radiologically it can be unilocular or multilocular or multilobular. ${ }^{12}$ Histologically it is of four types' unicystic, solid multicystic, extraosseous peripheral and desmoplastic. ${ }^{2}$ Treatment varies according to histological variant.

\section{Case Report}

A 36 year old male reported with a swelling on right side of lower jaw since 2 months and pain while chewing food since 3 weeks. Swelling was insidious in size and gradually increased to the present size. There was no history of trauma or tooth ache or decrease in size of swelling or any discharge from the swelling however patient was experiencing pain while chewing hot food. On clinical examination there was a solitary ill-defined diffused mild swelling over the right mandible on the lower $3^{\text {rd }}$ of the face. (Fig. 1) measuring about $6 \times 3 \mathrm{~cm}$ extending Medio laterally $2 \mathrm{~cm}$ lateral to the midline on the right side till the angle of the mandible and superiorinferiorly from the corner of the mouth to lower border of the mandible. The surface was smooth and the skin overlying the swelling was not much stretched or distended and was of normal colour and texture of skin with no secondary changes to be found. It was tender and hard to the palpating fingers. An intraoral examination revealed an ill-defined, solitary swelling in the right lower posterior buccal vestibule extending anteroposteriorly from canine to the third molar region and mediolaterally $1.5 \mathrm{~cm}$ from the buccal surface of molars towards the interdental gingiva of the involved teeth (Fig. 2). The mucosa overlying was stretched but was similar to the adjacent mucosal colour. It was tender and hard in consistency with buccal cortical plate expansion. Considering the clinical findings, we came to a tentative diagnosis of benign tumor of right side lower jaw. Ameloblastoma was the primary differential diagnosis. Incisional biopsy was performed subjected to histopathological examination. Orthopantamogram elicited a well-defined radiolucency with scalloped border involving the periapical region from the right lower central incisor to the first molar .Root resorption was present with the premolars and first molars. Lower border of the mandible was intact with $3 \mathrm{~mm}$ solid bone against the radiolucency. (Fig. 3) Histopathological examination showed multiple strands and islands of odontogenic epithelium with peripheral hyper chromatic palisaded cuboidal cells and central stellate cells. Focal areas of squamous metaplasia and associated stroma has dense collagen fibers with multiple island of odontogenic epithelium suggestive of ameloblastoma of acanthomatous type. Treatment implicated for the management of lesion included excision, curettage and chemical cauterization with Carnoys Solution leaving the lower border intact. Routine hematological investigations, chest radiograph, Electrocardiogram and pre anesthetic checkup was performed before taking the patient under general anesthesia. Extraction of the involved tooth was done, a trapezoidal flap with bilateral relieving limb was given, and lesion was exposed. Complete excision of the lesion was done with thorough curettage and smoothening of borders with round bur with copious betadine irrigation. (Fig. 4) Carnoy's solution was used for chemical cauterization. Lingual perforation was present on the cortex of $2^{\text {nd }}$ premolar region. A 12 hole reconstruction plate fixed $1 \mathrm{~cm}$ above 
the lower border of mandible leaving $5 \mathrm{~mm}$ from the apices of roots as a safe side to prevent fracture of mandible from occlusal forces. (Fig. 5) Support for fixation of reconstruction plate was taken bilaterally from buccal cortex. Medicated gauze pack was kept in the defect and water tight closure was done. Medicated gauze pack was removed after 48 hours. Patient was kept under I.V drugs and discharged after 3 days. (Fig. 6)

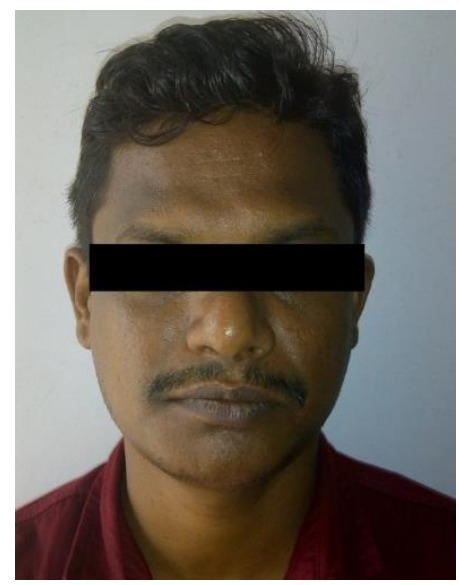

Fig. 1: Extra Oral Photograph of the Patient

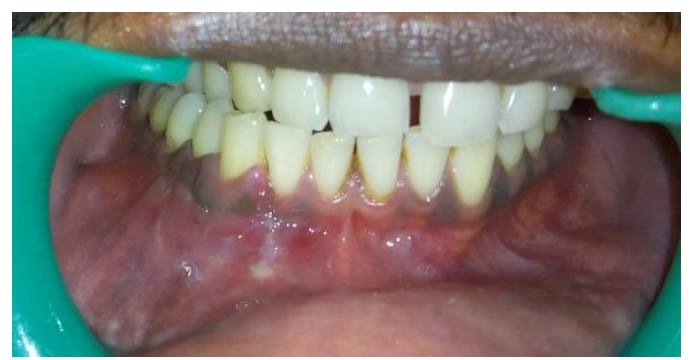

Fig. 2: Intra Oral Photograph of the Patient

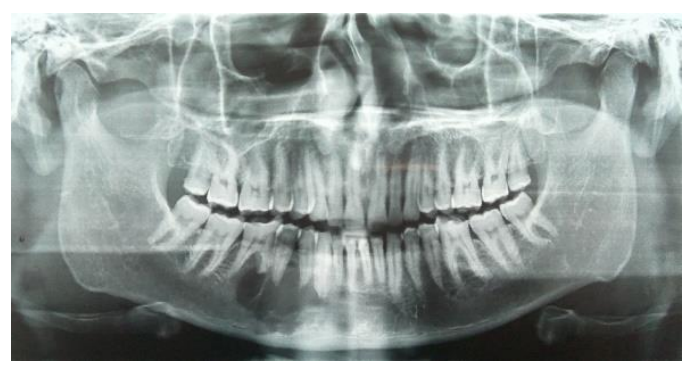

Fig. 3: Orthopantomogram

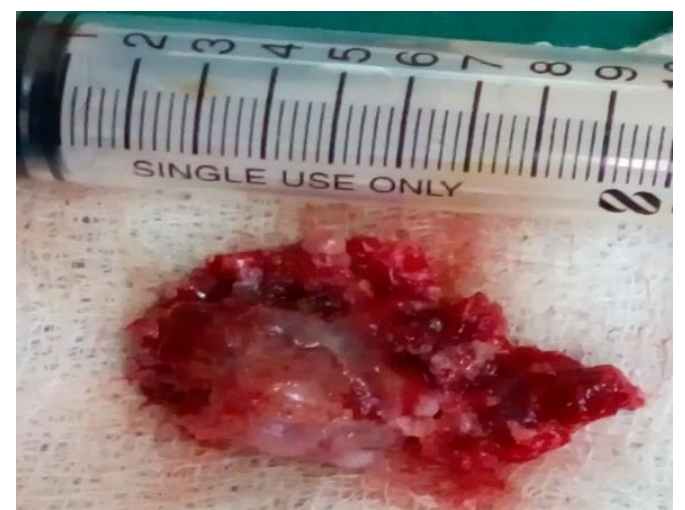

Fig. 4: Excised Lesion

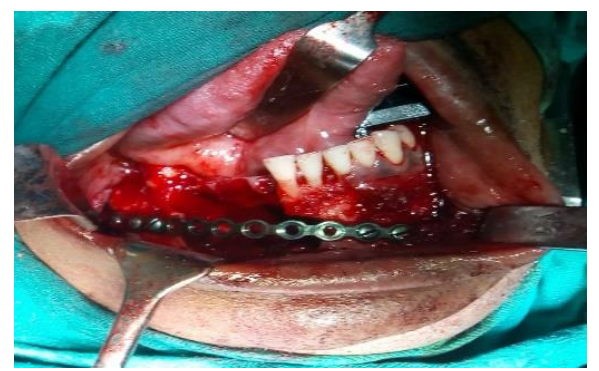

Fig. 5: Reconstruction plate Fixation

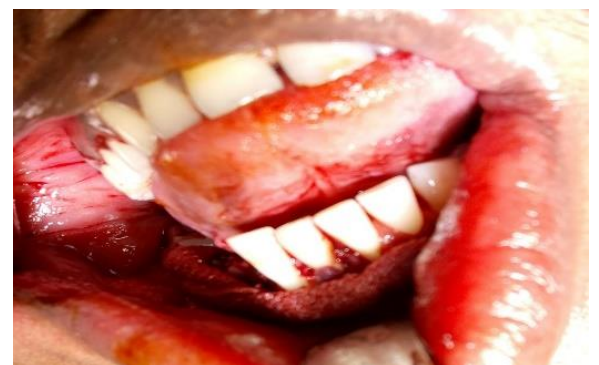

Fig. 6: Post-Operative Medicated Gauze

\section{Discussion}

The recurrence rate of unicystic and solid multicystic ameloblastomas ranges widely and depends on histological subtype ${ }^{13}$ usually small unicystic lesions are managed by enucleation as they are less likely to recur. But, in background the lesions other than unicystic or giant unicystic lesions had higher chance of recurrence. So the preferable option comes out as jaw resection. This approach has become more common due to wider options of microvascular grafts which are reliable to repair the defect. It is still a dilemmatic question for the operating surgeons about the merits and demerits of ameloblastomas to hand for aggressive approach.no doubt the published literature elicits that in the decades of 1940's to 1970's as per the advances in maxillofacial surgical field, enucleation was the preferable option compared to resection and reconstruction in ameloblastoma cases. ${ }^{14-21}$ Huge blow was given by Stoelinga to the literature when he proved the reduction in recurrence of keratocyst from 60 percent to less than 10 percent by using carnoy's solution which 
was very much beneficial to treat ameloblastoma's by chemical cauterization. ${ }^{22-23}$ Some authors have reported that the multilocular appearance is the most common radiological finding. ${ }^{24}$ But, some suggest follicular pattern is the dominant histological type..$^{25-26}$

\section{Conclusion}

Epidemiological variations are a pointer to variations in the experience of different groups, which may be better explained in terms of differences, awareness of condition and availability of facilities and resource personal for early diagnosis and treatment. Every case of ameloblastoma must be planned properly to increase the quality of life of patients.

\section{References}

1. Textbook of Oral and Maxillofacial Surgery, S.M. Balaji. 1st Edition. p: 363.

2. Gardner DG, Heikinheimo K, Shear M, Philipsen HP, Coleman H. Ameloblastomas. In: Barnes L, Eveson JW, Reichart P, Sidransky D, editors. World Health Organization classification of tumors. Pathology and genetics: head and neck tumours. Lyon: IARC Press; 2005. p. 296-300.

3. Cusack JW. Report of the amputations of portions of the lower jaw. Dublin Hospital Record 1827;4:1-38

4. Malassez L. On the role of epithelial debris around the teeth (in French). Archives de Physiologie Normale et Pathologique 1885 3e serie;5:309-40 and 6:379-449.

5. Reichart PA, Philipsen HP, Sonner S, Ameloblastoma:. biological profile of 3677 cases. Eur J Cancer B Oral Oncol 1995;31B:86-99.

6. Cameron HM. Oral tumours in Kenya. Pathol Microbiol (Basel) 1973;39:187-95.

7. Mosadomi A. Odontogenic tumours in African population. An analysis of 29 cases seen over 5-year period. Oral Surg Oral Med Oral Pathol 1975;40:50221.

8. Edington GM, Sheiham A. Salivary gland tunours and tumour of the oral cavity in western Nigeria. Br J Cancer 1966;20:425-33.

9. Adekeye EO. Ameloblastoma of the jaws: a survey of 109 Nigerian patients. J Oral Surg 1980;38:36-41.

10. Mitchell DA, Mitchell L. Oxford handbook of clinical dentistry.. 3rd ed. New York: Oxford University Press; 2003. p. 424.

11. Akinosi JO, Williams AO. Ameloblastoma in Ibadan, Nigeria. Oral Surg Oral Med Oral Pathol 1969;27:25765.

12. Chapelle KA, Stoelinga PJ, de Wilde PC, Brouns JJ, Voorsmit RA. Rational approach to diagnosis and treatment of ameloblastomas and odontogenic keratocysts. Br J Oral Maxillofac Surg 2004;42:381-90.

13. Nakamura N, Higuchi Y, Mitsuyasu T, Sandra F, Ohishi M. Comparison of long-term results between different approaches to ameloblastoma. Oral Surg Oral Med Oral Pathol Oral Radiol Endod 2002;93:13-20.

14. Small IA, Waldron CA. Ameloblastomas of the jaws. Oral Surg Oral Med Oral Pathol 1955;8:281-97.

15. Gardner AF, Apter MB, Axelrod JH. A study of twentyone instances of ameloblastoma, a tumor of odontogenic origin. Oral Surg Anesth Hosp Dent Serv 1963;21:230-7.

16. Masson JK, McDonald JR, Figi FA. Adamantinoma of the jaws: a clinicopathologic study of 100 histologically proved cases. Plast Reconstr Surg Transplant Bull 1959;23:510-25.

17. Monks FT. Treatment of adamantinoma by conservative surgery: a review. J Oral Surg Anesth Hosp Dent Serv 1964;22:171-7.

18. Georgiade N, Masters F, Horton C, Pickrell K. The ameloblastoma (adamantinoma) and its surgical treatment. Plast Reconstr Surg (1946) 1955;15:6-14.

19. Goldwyn R, Constable J, Murray JE. Ameloblastoma of the jaw. A clinical study. N Engl J Med 1963;269:126-9.

20. Gorlin RJ. The pathology of ameloblastomas and its relationship to treatment. Trans Int Conf Oral Surg 1970:230-53.

21. Stout RA, Lynch JB, Lewis SR. The conservative approach to ameloblastomas of the mandible. Plast Reconstr Surg 1963;31:554-62.

22. Stoelinga PJ. Long-term follow-up on keratocysts treated according to a defined protocol. Int J Oral Maxillofac Surg 2001;30:14-25.

23. Stoelinga PJ, Bronkhorst FB. The incidence, multiple presentation and recurrence of aggressive cysts of the jaws. J Craniomaxillofac Surg 1988;16:184-95.

24. Ogunsalu C, Daisley H, Henry K, et al. A new radiological classification for ameloblastoma based on analysis of 19 cases. West Indian Med J 2006;55:434-9.

25. Adebiyi KE, Odukoya O, Taiwo EO. Ectodermal odontogenic tumours: analysis of 197 Nigerian cases. Int J Oral Maxillofac Surg 2004;33:766-70.

26. Adebiyi KE, Ugboko VI, Omoniyi-Esan GO, et al. Clinicopathological analysis of histological variants of ameloblastoma in a suburban Nigerian population. Head and Neck Med 2006;2:42. 